Health \& Medicine | Miguel Hernández-Bronchud

\section{Placental immune editing switches (PIES) and cancer progression}

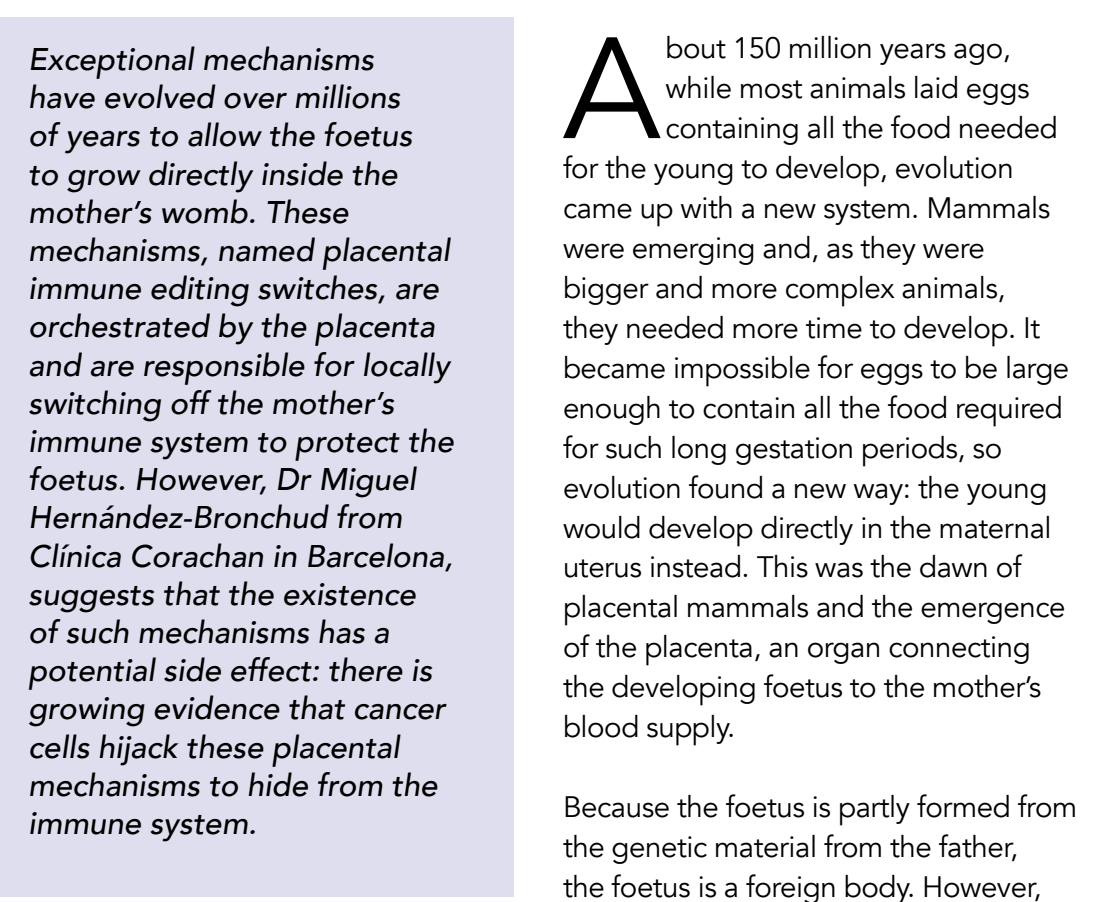

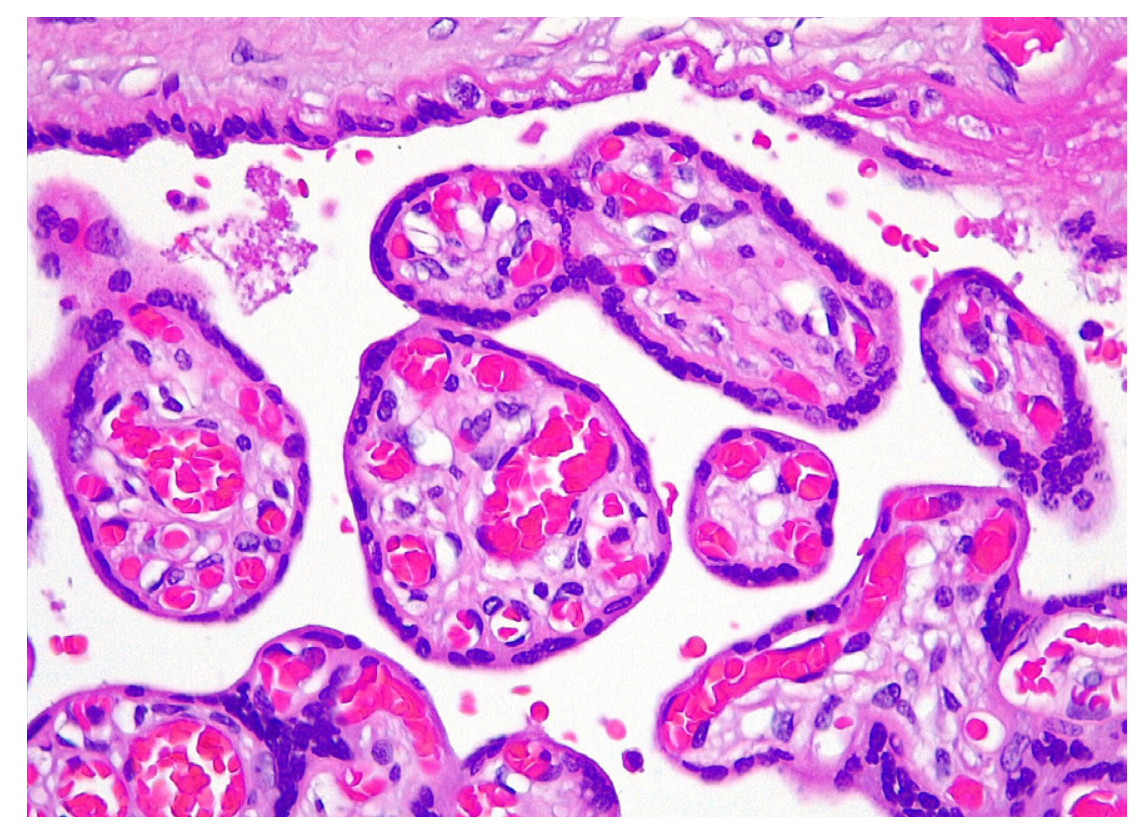

The placenta: Placental evolution was associated with development of placental immune editing
switches (PIES) that locally switch off the maternal immune system, allowing the mother's body accept and even protect the foetus. reject the foetus like it would reject any other foreign body; placental evolution was associated with the development of editing switches (PIES) that locally switch off the maternalimmune system so that the mother's body accepts and even protects the foetus, But the existence of PIES may have, as Dr HernándezBronchud calls it, a side effect: cancer cells are suspected to hijack these regulatory mechanisms to escape immunosurveillance.

PLACENTA AND

FOETO-MATERNAL TOLERANCE About a week after conception, the embryo implants into the uterine wal as a blastocyst, an embryonic stage during which an outer layer of cells called the trophectoderm surrounds the iner mass cell. While the embryo itself originates from the inner mass cell, the the to form the placenta.

Serving as a barrier between the immune systems of the mother and the foetus, the placenta plays a key role in foeto-maternal tolerance: it is in the placenta that regulatory mechanisms known as PIES are initiated, creating a where the materna mmune system is more tolerant. The any offensive that the maternal immun

\section{THE ROLES OF}

\section{TRANSPOSABLE ELEMENTS}

Transposable elements (TEs) are DNA sequences that play a major part in the maternal immune system does not system could otherwise launch. evolution: due to their ability to change their location within the genome, and enable the establishment of new mechanisms. Some TEs, called human endogenous retrovinses, may even originate from ancient retroviral infections during which viruses inserted their genome into host cells and viral. genes became integrant part of the human genome.

TE expression is tightly regulated. DNA methylation, involving addition of methyl groups (carbon atoms each bonded to three hydrogen atoms) onto DNA, prevents the gene from interacting with proteins, therefore silenceing it. In healthy cells, TEs are usually methylated thus almost completely silenced. exception: some TEs are demethylated and active. Transcription factors (e in genomics and epigenetic analysis of a single pregnant breast cancer patient several interesting changes Nuclear Factor of Activated T-cells or NFAT family) can then bind to them and promote the expression of nearby genes. Amongst other things, this leads placental cells to wear on their surface proteins named immune checkpoints. Immune checkpoints physiologically protect healthy cells from a strong immune response by sending an "Off" signal to immune cells. This at least

placental cells locally switch off the placenal inm foeto-maternal tolerance.

\section{WHY CANCER NEEDS} MMUUNOTOLERANC Carcinogenesis happens when norma cells are altered by mutations and become cancerous. Cancerous cells divide uncontrollably and may acquire the ability to infiltrate and destroy healthy body tissues.

Everyone during their life accumulates potentially carcinogenic mutations, but not everyone develops a cancer because the immune system is usually able to This detection is possible becalse, due

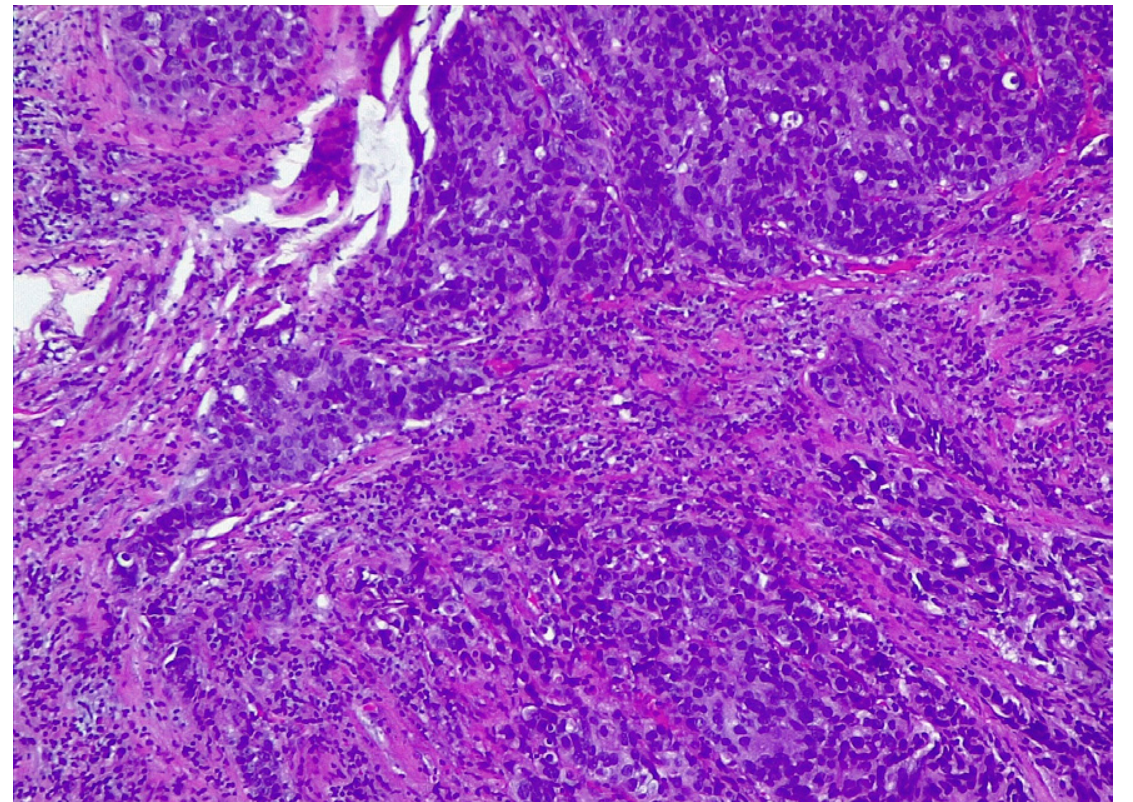

Breast carcinoma and Tumour Infiltrating Lymphocytes (TLLs): Dr Miguel Hernández-Bronchud

to the mutations, proteins expressed on the cell surface are modified and therefore recognised as foreign by the immune system. The more mutations a cell accumulates, the more likely it is to become cancerous, but a higher number of mutations also increases its detected by the immune Because regulatory mechanisms to switch off the immune system already xist, cancerous cells do not need to invent new ones.

modified proteins on its surface. Most cancers are therefore destroyed bost they can become a threat.

However, cancer immune escape sometimes happens. Aggressive cancers display modified proteins on their surface, yet this does not appear to compromise cancer progression: the cancer keeps growing and spreading, out of control from the immune system. Immunotolerance facilitates and may and for its metastases to develop.

\section{MIMICKING PLACENTAL CELLS} MICKING PLACENTAL CELLS the plant and just like the placenta involes the terine wall, cancer invades healthy issues. While the placenta orchestrates oeto-maternal tolerance, creating an inmunosuppressive microenvironm benefits from immunotolerance: in an mmunosuppressive microenvironment like the one created by placental cells, cancer can develop and express new without being targeted by the immune system. Because regulatory mechanisms to
switch off the switch off the immune system cancerous cells do not ned to invent new ones: they can just copy the genetic programmes carefully developed and refined over millions of years.

This theory was further confirmed during a case study conducted by Dr Hernandez-Bronchud. The patient was a pregnant woman who also had a breast cancer. The team observed that several dozen immune regulatory genes which pece physiologically overexpressed in placental cells were also pathologically overexpressed in cancer cells. The team also identified genes that were silenced Santal and cancer cells.

Some changes in gene expression observed in both placental and cancer 


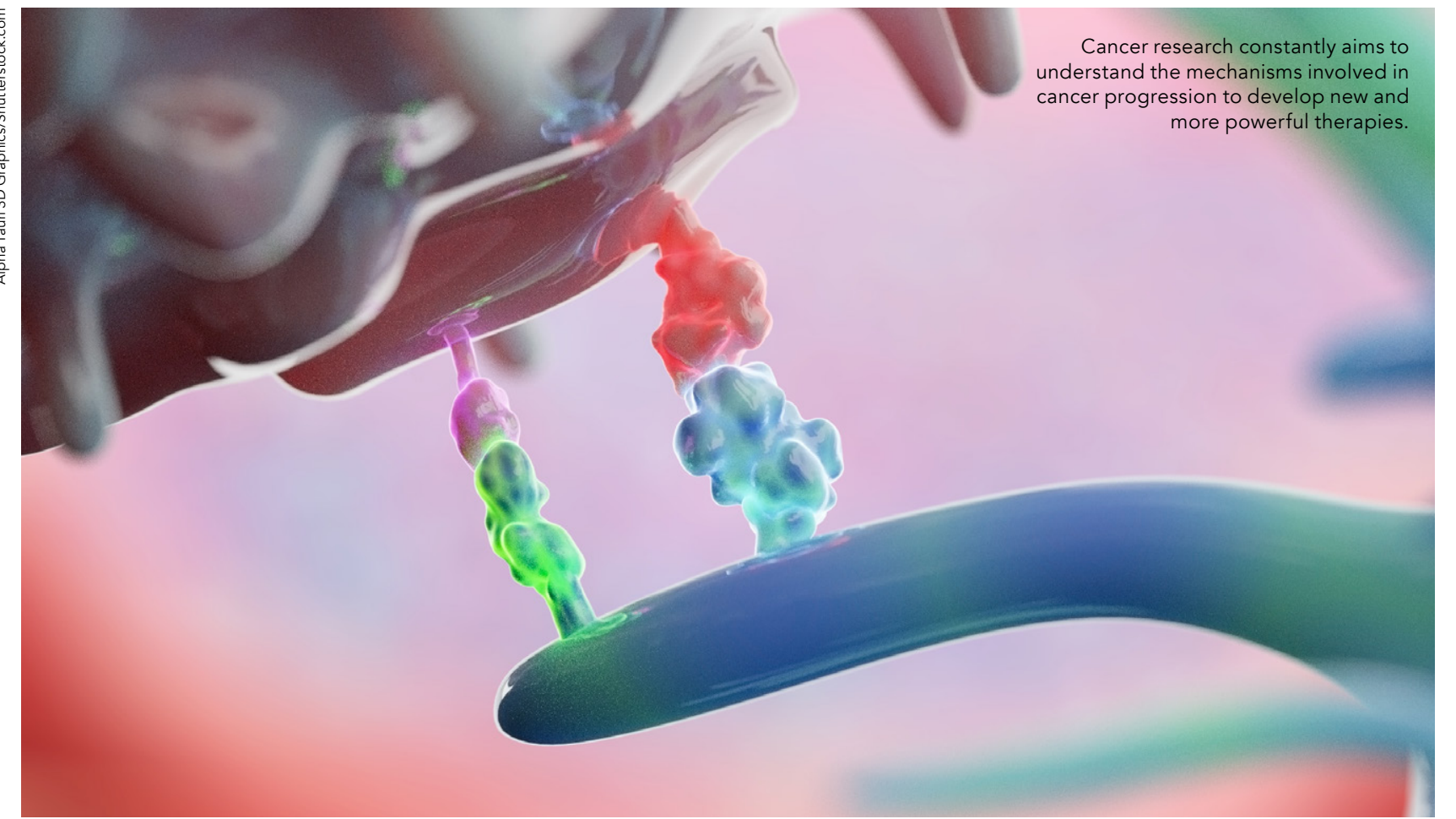

cells are related to the demethylation of to immunosuppressive landscapes in the tumour microenvironment (TME),

Allison and Tasuku Honjo, for their TEs. Indeed, Dr Hernández-Bronchud and his team noticed that methylation genes, including p53, PTEN, RB1 and discovery of a new way to treat cancer, Instead of acting on cancer cells directly those in placental cells: TEs were demethylated an therefore active, able to overexpress or silence genes, while they are normally silenced. Preliminary evidence suggests that cancer redeploys the regulatory mechaniss to mic placental cells though DNA physiologically active in the placenta phsiologise mostly silne placenta cells, are pathologically activated in cancer. During early development, TEs contribute to the expression of genes involved in growth, proliferation and invasion of placental cells, and in immune regulation. These functions, though not essential in healthy cells, are hallmarks of cancer. In cancer cells, demethylated TEs would therefore promote the expression of genes contributing to cancer proliferatio and invasion, and switch off the immune system. that deletion or under expression of like convention immune checkpoint immune system. They target immun checkpoints, these placental cells.

ARF, have been implicated in immune responses and inflammatory diseases. In particular, the p53 tumour-suppress pathway is involved in crucial aspects responses. Muñoz-Fontela et al. (2016) have also shown that oncoimmunology related molecules may play key tumour

\section{CANCER IMMUNE THERAPIES} Resistance to cancer immune therap is a challenge in treating cancer. Chemotherapy, which kills cancer cells, can work for a while but the most aggressive cancers often find ways to develop resistance mechanisms. Cancer research constantly aims to understan the mechanisms involved in cancer progression to develop new and more powerful therapies.

In 2018, the Nobel Prize in Physiology or Medicine was awarded to James

: mhbronchud@gmail.com T: 0034609640857

\section{References}

Bronchud M. H. (2020). Alpha and Omega: from the Sagrada Familia to Placenta and Cancer. Journal of Science, Humanities and Arts, [Online] 7(3). https:// doi.org/10.17160/josha.7.3.677

Bronchud M. H., et al. (2016). Placental immune editing switch (PIES): learning about immunomodulatory pathways from a unique case org/10.18632/oncotarget.13306

Bronchud M. H., et al. (2017). Epigenetic changes found in uterine decidual and placental tissues can also be found in the breast cancer microenvironment of the same unique patient. description and potential interpretations. Oncotarget, 9(5), 6028-6041. https:// doi.org/10.18632/oncotarget.2348

Bronchud M. H. (2019). Do locally advanced and metastatic human epithelial cancers evolve in 'placental/decidual-like microenvironments'? Clinical \& translational oncology: official publication of the Federation of Spanish Oncology Societies and of the National Cancer Institute of Mexico, 21(2), 160-166. https://doi.org/10.1007/s12094-018-1982-5

Bronchud M. H. (2018). Are aggressive epithelial cancers 'a disease' of Eutherian mammals? Ecancermedicalscience, 12, 840. https://doi. org/10.3332/ecancer.2018.840

Bronchud M. H. (2017). Immunomodulatory pathways in both breast cancer and placental tissues: Insights from a unique clical and genomic case report. J Clin Oncol, [Online] 35(7). https://doi.org/10.1200/ JCO.2017.35.7_suppl.13

Lynch-Sutherland C. F., et al. (2020). Reawakening the Developmental Origins of Cancer Through OOnlinel 10,468 htps:/doiorg/10 3389/ fonc.2020.00468

Muñoz-Fontela, C., et al. (2016). Emerging roles of p53 and other tumour-suppressor genes in immun regulation. Nat Rev Immunol, 16, 741-750 https://doi. org/10.1038/nri.2016.99

\section{Research Objectives}

Dr Miguel Hernández-Bronchud has 35 years of clinical experience in oncology, with a special interest in breast

\section{Detail}

Miguel Hernández-Bronchud GCCC360 Plaza Manuel Corachan 1 08017 Barcelona, Spain

Miguel Hernández-Bronchud graduated from both Cambridge (BA, MA Natural Sciences 1980) and Oxford Medical School (BM BCh 1983, DM 1990), with cancer research and clinical training at the Royal Marsden Hospita (London) and at the Christie (Manchester). He is now a practicing medical oncologist at Genesis Care Oncology Corachán in Barcelona.

\section{Personal Response}

Do you think pregnancy (and the fact that the mechanisms involved in foeto-maternal tolerance are already physiologically activated) can make cancer cells more likely to hijack these placent

No. In general, cancer during pregnancy is an uncommon occurrence. Only 1 in every 1,000 pregnant women are diagnosed with cancer, even if the number of pregnant women with cancer is likely to increase because children.

Cumulative carcinogenic mutations (the hallmark of cancer but extremely unusual in placental tissues, excep in rare chonccarifing

It is probably mutations in regulatory genes (oncogenes, TEs and transcription factor genes) that are likely to healthline.com/health/cancer-in-pregnancy 